\title{
Ab initio studies of ethanol dehydrogenation at binary AuPd nanocatalysts
}

\author{
L. M. Molina, ${ }^{1, \text { a) }}$ A. Benito, ${ }^{1}$ and J. A. Alonso ${ }^{1}$ \\ Departamento de Física Teórica, Atómica y Optica, Universidad de Valladolid, E-47011 Valladolid, \\ Spain.
}

(Dated: 18 January 2018)

Density Functional Theory (DFT) simulations have been performed to study ethanol anaerobic oxidation at ten-atoms binary gold-palladium clusters with varying compositions, ranging from $0 \%$ to $100 \%$ gold content. For each case, we have studied the loss of two hydrogen atoms, the desorption of acetaldehyde, and recombination of hydrogen into gas-phase $\mathrm{H}_{2}$. The results show that alloying produces sizable changes in the reaction barriers and in the stability of the intermediate species, which are related to different intrinsic reactivities of palladium and gold.

KEYWORDS: DFT calculations; ethanol oxidation; $\mathrm{Au}-\mathrm{Pd}$; bimetallic catalyst; reaction intermediates

\section{INTRODUCTION}

Selective oxidation of alcohols to various carbonylic compounds over heterogenous catalysts is a very important process for the sustainable synthesis of fine chemicals and intermediates ${ }^{1,2}$. For such reactions, gold nanocatalysts have proved not only active, but also exceptionally selective for numerous reactions ${ }^{3-5}$. One particularly interesting case is the selective production of aldehydes; various studies suggest that the main reaction mechanism involves two steps: dissociation of the alcohol $\mathrm{O}-\mathrm{H}$ bond with formation of a metal-alkoxy intermediate, followed by breaking of the $\mathrm{C}-\mathrm{H}$ bond, forming the aldehyde and a metal-hydride intermediate ${ }^{6-8}$.

One trivial consequence of such complex reaction mechanism is that very diverse characteristics of the catalyst can dramatically influence both reactivity and selectivity: size and type of support currently being the most carefully analyzed ${ }^{9,10}$. Very recently, the study of bimetallic nanocatalysts has added even more complexity and richness to the problem. Alloyed clusters and nanoparticles have completely new and interesting properties ${ }^{11}$, and their catalytic applications are rapidly expading ${ }^{12-14}$. One crucial example is the discovery of very high selectivity for aldehyde production when gold and palladium are alloyed into bimetallic nanoparticles ${ }^{15,16}$. For selected compositions, there is a much better performance of the catalyst, when compared to similar situations with either pure $\mathrm{Au}$ or Pd nanoparticles.

Despite extensive experimental research ${ }^{17-19}$, the reasons behind such improvement upon alloying are not at all clear. Mixing two metals introduces sizable changes on the adsorption energies and on the height of reaction barriers, thus profoundly affecting both activity and selectivity of the catalyst. While there are some theoretical studies treating adsorption of other molecules at

a) Electronic mail: lmolina@fta.uva.es
$\mathrm{Au}-\mathrm{Pd}$ nanoparticles ${ }^{20,21}$, in the case of alcohols the data on their interaction with bimetallic Au-Pd alloys is very scarce $^{22}$. This has motivated us to perform an extensive study of ethanol $\left(\mathrm{CH}_{3} \mathrm{CH}_{2} \mathrm{OH}\right)$ dehydrogenation to acetaldehyde at selected models of $\mathrm{Au}_{x} \mathrm{Pd}_{1-x}$ catalysts, varying uniformly their composition from 0 to $100 \%$ palladium. This allows us to analyze the effect of alloying on the key steps of reaction, by comparing the stability of adsorbed species, as well as the height of reaction barriers, among various compositions.

As a first approach to this complex problem, we have restricted the study to anaerobic reaction conditions, investigating the production of acetaldehyde in the absence of preadsorbed oxygen. Apart from reducing the complexity of the study, such conditions are interesting for possible applications in other reactions where hydrogen or other interesting hydrogenated species are produced. For simplicity, and in order to keep computational costs low, we perform this study on free clusters with a size of ten atoms. Such simple model system has many features in common with real nanocatalysts, as for example the presence of many highly reactive low coordinated sites.

\section{COMPUTATIONAL SETUP}

Density Functional Theory (DFT) calculations were carried out using the projector augmented-wave method, as implemented in the GPAW code $^{23,24}$. Wave functions are expanded in a three-dimensional grid, with the spacing set to $0.2 \AA$. Each cluster was placed at the center of a large cubic cell $(17 \AA \times 17 \AA \times 17 \AA)$, thus making interactions between the wave-functions tails and the cell borders negligible. Exchange-correlation effects were modelled with the PBE functional ${ }^{25,26}$. The convergence threshold for the eigenstate energies was set to $5 \cdot 10^{-7}$ $\mathrm{eV} / \mathrm{e}^{-}$. Every initial structure was optimized using the BFGS (Quasi-Newton) algorithm ${ }^{27}$ until forces were below $0.01 \mathrm{eV} / \AA$. The calculations were performed without spin polarization; tests including spin effects for the bare $\mathrm{Au}_{x} \mathrm{Pd}_{y}$ clusters showed that the ones containing $\mathrm{Pd}$ have very weak magnetic effects, with the energy difference between spin-polarized and unpolarized calculations being only of around $0.05 \mathrm{eV}$. Furthermore, we 
also checked that ethanol absorption completely kills the residual magnetization, making the results obtained from unpolarized simulations completely equal to the ones with spin effects.

Energy barriers were calculated by a constrained minimization method, involving several simulations where the reaction coordinate $(\mathrm{H}-\mathrm{O}$ bond distance for the first barrier, and $\mathrm{C}-\mathrm{H}$ distance for the second one) was restricted at increasingly larger values, while allowing the rest of the system to freely relax ${ }^{28}$ (see details in the Supplementary Information). Transition state conformations were characterized as energy maxima in the reaction profile; because of the complexity of the adsorbed molecule, we took care of checking the saddle point character at the transition state by relaxing various candidate conformations at the critical value of the reaction coordinate. With this procedure, we obtained a precision for the calculated barrier heights of around $0.02 \mathrm{eV}$.

Since ethanol is a medium-sized molecule, dispersion interactions are expected to be non negligible. Therefore, we have added Grimme's DFT-D3 dispersion correction ${ }^{29}$ to the DFT-PBE binding energies. The value of such correction is quite uniform, and in all cases is of the order of $0.2 \mathrm{eV}$.

\section{RESULTS}

\section{A. Structures for alloyed clusters}

Previous to the reactivity studies, it is necessary to choose reasonable models for the alloyed Au-Pd clusters. Therefore, we have selected six compositions for a tenatoms free catalyst $\left(\mathrm{Pd}_{10}, \mathrm{Au}_{2} \mathrm{Pd}_{8}, \mathrm{Au}_{5} \mathrm{Pd}_{5}, \mathrm{Au}_{8} \mathrm{Pd}_{2}\right.$, $\mathrm{Au}_{9} \mathrm{Pd}_{1}$ and $\left.\mathrm{Au}_{10}\right)$, and we have subsequently performed a nonexhaustive isomer search for relatively stable conformations on each of these compositions. In our search, we have first considered several candidate 3D structures for either $\mathrm{Pd}_{10}$ and $\mathrm{Au}_{10}$. Then, for the alloyed clusters we have started from the most stable structures of the pure clusters and we have replaced some $\mathrm{Au}$ atoms by $\mathrm{Pd}$ ones (or viceversa), generating then several different permutational isomers (four or five) for each composition. It must be noted that more Au-rich compositions were included in the study as they were found much more interesting; as it will become clear later, the results for Pdrich compositions turned out to be fairly similar, making irrelevant the study of $\left.\mathrm{Au}_{1} \mathrm{Pd}_{9}\right)$. Figure 1 shows the relaxed structures of the most stable conformations found for all the binary compositions studied. In each case $\left(\mathrm{Au}_{x} \mathrm{Pd}_{y}\right.$ composition, with $\left.x+y=10\right)$, we give the binding energy per atom:

$$
E_{b}=\frac{1}{10}\left[E\left(A u_{x} P d_{y}\right)-x E(A u)-y E(P d)\right]
$$

as well as the mixing energy (which we define as the energy gain in the mixed cluster with respect to pure
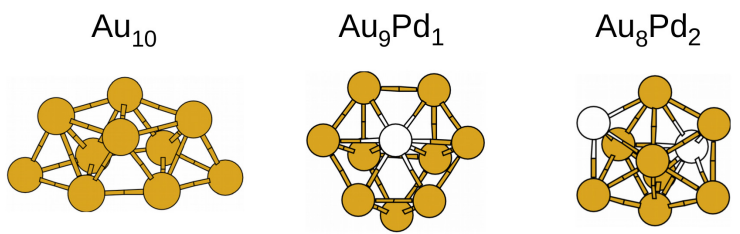

$$
E_{b}=-2.11 e V
$$

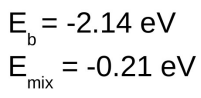

$E_{b}=-2.21 \mathrm{eV}$

$\mathrm{E}_{\text {mix }}=-0.88 \mathrm{eV}$
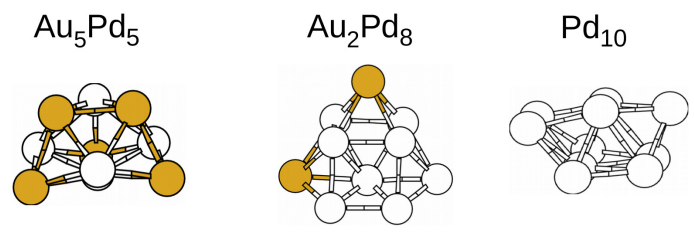

$$
\begin{aligned}
& E_{b}=-2.24 \mathrm{eV} \\
& E_{\text {mix }}=-0.82 \mathrm{eV}
\end{aligned}
$$$$
E_{b}=-2.25 \mathrm{eV}
$$$$
E_{b}=-2.22 \mathrm{eV}
$$

FIG. 1. Low energy structures found for 10-atoms $\mathrm{Au}_{x} \mathrm{Pd}_{y}$ clusters. Binding $\left(\mathrm{E}_{b}\right)$ and mixing $\left(\mathrm{E}_{\text {mix }}\right)$ energies are shown for each case. $\mathrm{Au}$ and $\mathrm{Pd}$ atoms are represented by yellow and white spheres, respectively.

$\mathrm{Au}_{10}$ and $\left.\mathrm{Pd}_{10}\right)$ :

$$
E_{m i x}=\left[E\left(A u_{x} P d_{y}\right)-\frac{x}{10} E\left(A u_{10}\right)-\frac{y}{10} E\left(P d_{10}\right)\right]
$$

It must be noted that, in order to establish meaningful comparisons between clusters of various compositions, we need to keep their structures relatively similar to each other; otherwise, it would be impossible to separate chemical effects purely due to varying composition, from chemical effects associated to a special structural configuration. This is the reason why we have restricted our isomer search to clusters with 3D structures (small Pd clusters prefer $3 \mathrm{D}$ structures ${ }^{30,31}$ ), in order to keep a structural uniformity across the whole range of compositions. Otherwise, we would have problems comparing $2 \mathrm{D}$ gold clusters with $3 \mathrm{D}$ alloyed structures, since the former ones possess unique chemical features caused by their shape ${ }^{32}$.

For the binary clusters, in all the cases the mixing energies are negative, with values between -0.5 and $-0.7 \mathrm{eV}$. This agrees with previous studies of the stability of binary Au-Pd clusters and nanoparticles ${ }^{30,33-35}$. Then, for small clusters, as it also happens for bulk alloys ${ }^{36}$, alloying of $\mathrm{Au}$ and $\mathrm{Pd}$ is energetically favourable. The tendency to mixing is consistent with the observation that the most negative values of the mixing energy take place for a palladium content between $20 \%$ and $50 \%$.

In the case of $\mathrm{Au}_{2} \mathrm{Pd}_{8}$ and $\mathrm{Au}_{8} \mathrm{Pd}_{2}$, we have checked that the tendency towards allowing favours conformations where the impurity atoms are separated from each other; alternate configurations with the impurities neighbour to each other are approximately $0.1 \mathrm{eV}$ less stable. 
In the Supporting Information, we show the results for simulations of the ethanol dehydrogenation reaction on these alternate conformations.

\section{B. Reaction at the pure $A \mathbf{u}_{10}$ cluster}

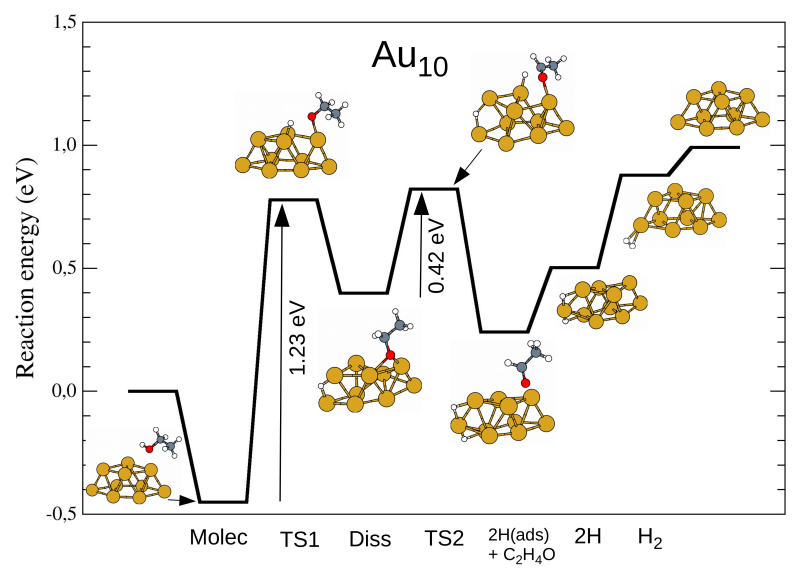

FIG. 2. Energy profile of ethanol dehydrogenation reaction at a $\mathrm{Au}_{10}$ cluster. In the ethanol molecule, grey, white and red small spheres represent $\mathrm{C}, \mathrm{H}$ and $\mathrm{O}$ atoms.

Let us now discuss the ethanol dehydrogenation reaction at each of the clusters, starting with the pure $\mathrm{Au}_{10}$ cluster. Figure 2 shows an energy profile including the most relevant reaction steps. The first one is the molecular adsorption of ethanol. By relaxing various adsorption configurations, we confirmed that (as found in other studies ${ }^{37,38}$ ) ethanol binds to the transition metal through its oxygen atom. In the Supporting Information we show the equilibrium structures and the binding energies of all the conformations considered (both for the $\mathrm{Au}_{10}$ case and for the rest of the clusters). In the case of the pure gold cluster, due to its quite noble character, the binding energy is moderate $(-0.45 \mathrm{eV})$ with a sizable O-Au bond distance $(2.39 \AA)$. The next stage involves the breaking of the $\mathrm{O}-\mathrm{H}$ bond. This is, by far, the most difficult reaction step, as it involves a relatively large (1.23 $\mathrm{eV}$ ) activation barrier. After hydrogen extraction, the oxygen atom in ethanol binds at a bridge-like site between two $\mathrm{Au}$ atoms. With respect to gas-phase ethanol, this state is unstable by around $0.4 \mathrm{eV}$, highlighting again the noble character of the gold cluster towards ethanol adsorption and dissociation.

The next stage involves the extraction of a second hydrogen atom, forming part, initially, of the $\mathrm{CH}_{2}$ group. The simulations show that this is a fairly easy step, with a moderate barrier of $0.42 \mathrm{eV}$. Then, the last stage of the reaction consists on the desorption of the produced acetaldehyde $\left(\mathrm{CH}_{3} \mathrm{CHO}\right)$ from the cluster, which takes only $0.26 \mathrm{eV}$. This completes the ethanol dehydrogenation. After that, full recovery of the catalytic power of the cluster requires the elimination of the hydrogen from the cluster, which closes the catalytic cycle. Formation of gas-phase $\mathrm{H}_{2}$ takes place in two steps: first, the two separated chemisorbed $\mathrm{H}$ atoms must recombine into an adsorbed $\mathrm{H}_{2}$ molecule. For $\mathrm{Au}_{10}$, this step requires only $0.34 \mathrm{eV}$. Second, the adsorbed $\mathrm{H}_{2}$ molecule must desorb to the gas phase, a very easy process which takes only $0.11 \mathrm{eV}$. As it happened for ethanol, the relatively noble character of gold results in a very weak binding of the adsorbed $\mathrm{H}_{2}$ molecule.

\section{Reaction at the pure $\mathbf{P d}_{10}$ cluster}

Next, we discuss the results obtained for the pure $\mathrm{Pd}_{10}$ cluster. Figure 3 shows the energy profile of the reaction, along a very similar pathway to the case of $\mathrm{Au}_{10}$. In comparison to gold, palladium is intrinsically more reactive; our results confirm this intuitive idea, as we find a systematically stronger binding of the various reaction intermediates. For example, the binding energy of ethanol rises now to $-0.64 \mathrm{eV}$. Also, the activation barrier for breaking the $\mathrm{O}-\mathrm{H}$ bond decreases to $0.98 \mathrm{eV}$, and the dissociated state is fairly stable, with a binding energy of $-0.82 \mathrm{eV}$ relative to gas phase ethanol (let us recall that, in the case of $\mathrm{Au}_{10}$, the energy of the dissociated state is $+0.40 \mathrm{eV}$ above).

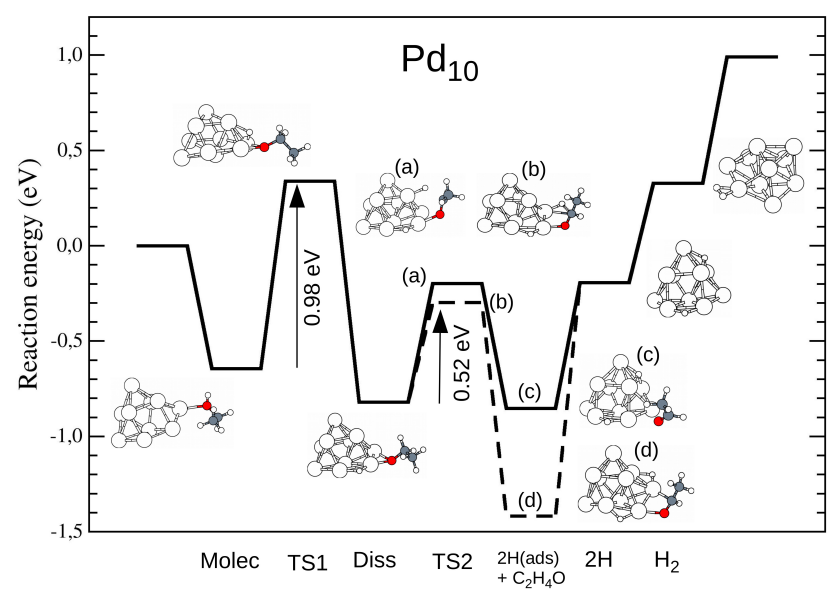

FIG. 3. Energy profile of ethanol dehydrogenation reaction at a $\mathrm{Pd}_{10}$ cluster.

The higher reactivity of $\mathrm{Pd}$ also causes some interesting changes in the second reaction step. Starting from dissociated ethanol, we have found two alternative pathways for the removal of the second $\mathrm{H}$ atom. The first one (see insets (a) and (c) in Figure 3) involves interaction of the hydrogen atom with a $\mathrm{Pd}$ atom neighbour to those bonded to ethanol. The second pathway (see insets (b) and (d)), involves the interaction of that hydrogen atom with one of the Pd atoms bonded to the oxygen atom. In the first case, after hydrogen removal, acetaldehyde is weakly bound to the cluster through the oxygen atom 
at a Pd-Pd bridge position. Interestingly, in the second case we find a strongly bound acetaldehyde intermediate complex (see inset (d)), having a sigma-like C-O bond, and two strong bonds with $\mathrm{Pd}$ atoms of the cluster, a Pd-carbon bond and a Pd-oxygen bond. Such intermediate is $0.56 \mathrm{eV}$ more stable than the one shown in inset (c). We have checked, by performing similar simulations in the case of pure $\mathrm{Au}_{10}$, that such doubly bonded acetaldehyde complex is not stable at the gold cluster. Its formation on palladium is, therefore, an intrinsic effect due to the higher reactivity of this metal. Acetaldehyde desorption to the gas phase from such strongly bonded intermediate requires $1.22 \mathrm{eV}$ (only $0.65 \mathrm{eV}$ from the intermediate (c)).

Finally, hydrogen recombination into adsorbed $\mathrm{H}_{2}$ takes around $0.5 \mathrm{eV}$ and $\mathrm{H}_{2}$ desorption an additional 0.6 $\mathrm{eV}$. Overall, the higher reactivity of $\mathrm{Pd}$ leads to stronger bonding for the reaction intermediates. While this is an advantage for the first part of the reaction, because of the lowering of the barriers, the high stability of both adsorbed acetaldehyde (which requires up to $1.2 \mathrm{eV}$ to desorbs) and dissociated hydrogen will probably affect the amount of available reaction sites and the overall reaction rates.

\section{Reaction at mixed $A u_{2} \mathbf{P d}_{8}, \mathrm{Au}_{5} \mathbf{P d}_{5}, \mathrm{Au}_{8} \mathbf{P d}_{2}$ and $\mathbf{A u} \mathbf{P d}_{1}$ clusters}

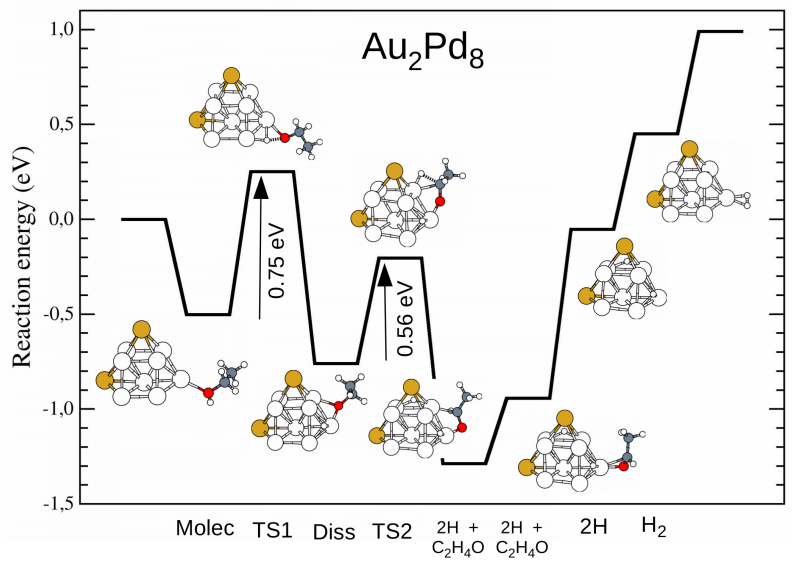

FIG. 4. Energy profile of ethanol dehydrogenation reaction at a $\mathrm{Au}_{2} \mathrm{Pd}_{8}$ cluster.

Now we analyze the effects of alloying on the previously discussed reaction pathways. Figure 4 shows the reaction profile for the $\mathrm{Au}_{2} \mathrm{Pd}_{8}$ cluster. In this case, we have a larger variety of sites $(\mathrm{Au}$ and $\mathrm{Pd})$ available for ethanol binding. Test simulations show a clear preference for $\mathrm{Pd}$ sites during the initial reaction steps (molecular adsorption of ethanol and dissociation of the first hydrogen atom). Once ethanol is adsorbed at a Pd site, surrounded by other Pd atoms and with the Au atoms relatively far away, the main features of the reaction pathway are quite similar to the results found for pure $\mathrm{Pd}_{10}$. The first reaction barrier is moderate $(0.75 \mathrm{eV})$, and the second one, $\mathrm{C}$ $\mathrm{H}$ bond breaking, is also quite low $(0.56 \mathrm{eV})$, with height very similar to the corresponding one for $\mathrm{Pd}_{10}$. Also, we find a highly stable doubly-bonded acetaldehyde intermediate. The similarities are not surprising, since the local chemical environment where the reaction takes place is very similar to that in the $\mathrm{Pd}_{10}$ case. The final reaction steps are also characterized by high reaction energies, given the large energy difference between the configuration with chemisorbed acetaldehyde and two $\mathrm{H}$ atoms, and the final state with gas-phase acetaldehyde and $\mathrm{H}_{2}$.

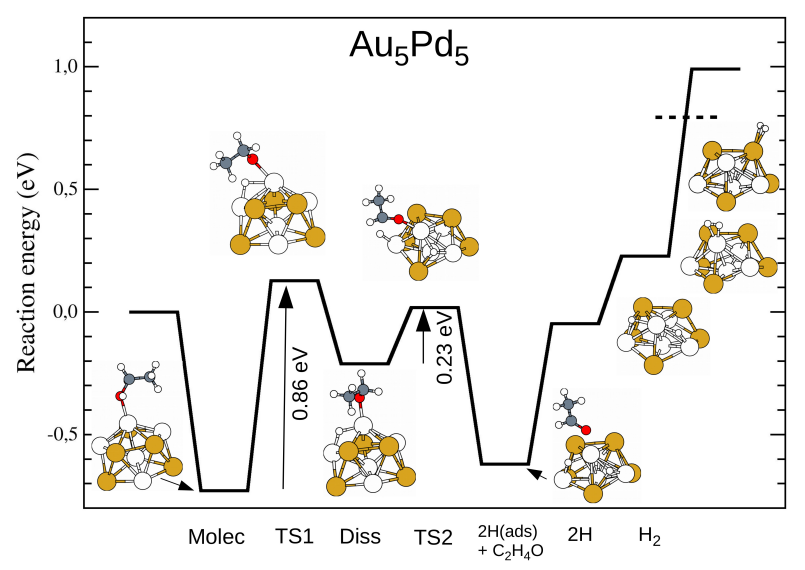

FIG. 5. Energy profile of ethanol dehydrogenation reaction at a $\mathrm{Au}_{5} \mathrm{Pd}_{5}$ cluster. For the last reaction step $\left(\mathrm{H}_{2}\right.$ adsorbed at the cluster) an alternate binding configuration is shown in a dashed line, with $\mathrm{H}_{2}$ bonded to a Au site.

Of all clusters under study, $\mathrm{Au}_{5} \mathrm{Pd}_{5}$, corresponding to $50 \%$ concentration of each component, has the largest binding energy for molecular adsorption of ethanol, -0.73 $\mathrm{eV}$, which is adsorbed at a $\mathrm{Pd}$ site (see Figure 5). The barrier for $\mathrm{O}-\mathrm{H}$ dissociation is moderate, amounting to $0.86 \mathrm{eV}$. It is, in fact, lower than the corresponding barriers on $\mathrm{Pd}_{10}$ and $\mathrm{Au}_{10}$. Then, the intermediate state with dissociated ethanol is characterized by a binding energy of $-0.21 \mathrm{eV}$, which is approximately halfway between the $-0.8 \mathrm{eV}$ value for $\mathrm{Pt}_{10}$ and the $+0.4 \mathrm{eV}$ for $\mathrm{Au}_{10}$. The second reaction barrier, of $0.23 \mathrm{eV}$, is now much smaller than the first one, and it involves reaction of the second hydrogen atom with a Pd atom. Again, the stability of the state with adsorbed acetaldehyde, with a binding energy of around $-0.6 \mathrm{eV}$, is intermediate between the ones found for $\mathrm{Pt}_{10}$ and $\mathrm{Au}_{10}$. Then, it takes $0.57 \mathrm{eV}$ for the acetaldehyde molecule to desorb. Recombination of the two hydrogen atoms into adsorbed $\mathrm{H}_{2}$ is energetically inexpensive, but final $\mathrm{H}_{2}$ desorption is as difficult as in the pure $\mathrm{Pd}_{10}$ case; this is due to the binding of molecular $\mathrm{H}_{2}$ to a reactive $\mathrm{Pd}$ site, highly preferred over the neighbouring Au sites. This last stage is likely to take place in two steps, as the figure shows; in the first one, $\mathrm{H}_{2}$ will migrate from the $\mathrm{Pd}$ site to a neighbour $\mathrm{Au}$ site; the energetic cost of this step is about $0.55 \mathrm{eV}$. Then, the 
second and final step will be desorption of $\mathrm{H}_{2}$ from the $\mathrm{Au}$ site, which takes only $0.2 \mathrm{eV}$.

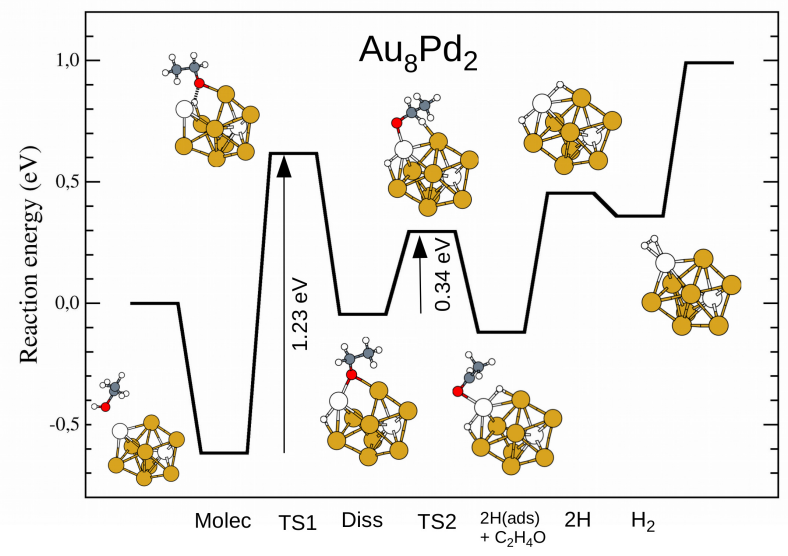

FIG. 6. Energy profile of ethanol dehydrogenation reaction at a $\mathrm{Au}_{8} \mathrm{Pd}_{2}$ cluster.

The results for the $\mathrm{Au}_{8} \mathrm{Pd}_{2}$ cluster are shown in Figure 6. As expected, initial adsorption of ethanol takes place at a more reactive $\mathrm{Pd}$ site. The presence of many neighbouring $\mathrm{Au}$ atoms results in a high barrier for $\mathrm{O}$ $\mathrm{H}$ dissociation $(1.23 \mathrm{eV})$, with the final dissociated state characterized by a hydrogen atom at a $\mathrm{Pd}$-Au bridging site, and by oxygen bound at a neighbour $\mathrm{Pd}-\mathrm{Au}$ bridging site. The stability of such intermediate state is similar to the $\mathrm{Au}_{5} \mathrm{Pd}_{5}$ case. Then, the $\mathrm{C}-\mathrm{H}$ bond breaks with a quite small energy barrier of $0.34 \mathrm{eV}$. The lower reactivity of $\mathrm{Au}$ sites (both of the dissociated hydrogen atoms bind at $\mathrm{Pd}-\mathrm{Au}$ bridging sites) results in a relatively unstable $2 \mathrm{H}+\mathrm{C}_{2} \mathrm{H}_{4} \mathrm{O}$ adsorbed configuration. Then, acetaldehyde desorption needs again around $0.5 \mathrm{eV}$, which can be explained in terms of this molecule binding to a $\mathrm{Pd}$ site (binding at $\mathrm{Au}$ sites, as in the pure $\mathrm{Au}_{10}$ case, leads to a much smaller acetaldehyde binding energy). The final reaction stage, hydrogen recombination and desorption of $\mathrm{H}_{2}$, has some unusual features due to the cluster structure. The presence of only two separated Pd sites causes the state with two dissociated hydrogen atoms to become relatively unstable, and their recombination into molecular $\mathrm{H}_{2}$ adsorbed at a $\mathrm{Pd}$ site is actually exothemic. Comparing the results with the $\mathrm{Au}_{10}$ case, we see that the presence of just two surface $\mathrm{Pd}$ atoms causes important changes, as ethanol preferentially binds and dissociates at those $\mathrm{Pd}$ sites.

Finally, we have considered the case of $\mathrm{Au}_{9} \mathrm{Pd}_{1}$ (that is, further decreasing the palladium content to just one atom). The results, shown in Figure 7, are quantitetively very similar to the ones for $\mathrm{Au}_{8} \mathrm{Pd}_{2}$. The stabilities of reaction intermediates as well as the height of the reaction barriers are almost equal to the ones for the cluster containing two palladium atoms. We find, however, an interesting qualitatively difference. Initial adsorption of molecular ethanol takes place at a Au site, instead of the usual Pd site. Such behaviour can be easily interpreted

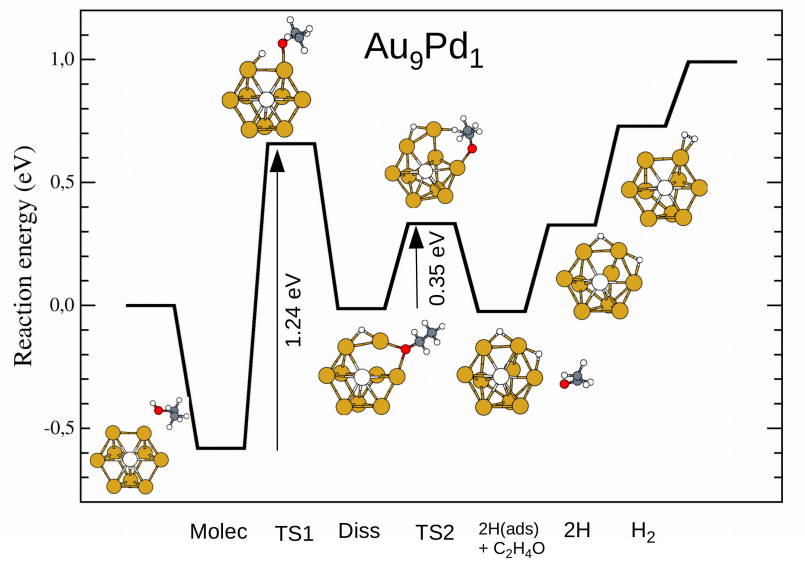

FIG. 7. Energy profile of ethanol dehydrogenation reaction at a $\mathrm{Au}_{9} \mathrm{Pd}_{1}$ cluster.

in terms of the special equilibrium structure for this cluster, where the $\mathrm{Pd}$ atom is highly coordinated (with $9 \mathrm{Au}$ neighbours), thus rendering it less active than the neighbour low-coordinated gold atoms. Besides, the presence of palladium increases a litle bit the reactivity of those gold sites, with respect to the pure $\mathrm{Au}_{10}$ case.

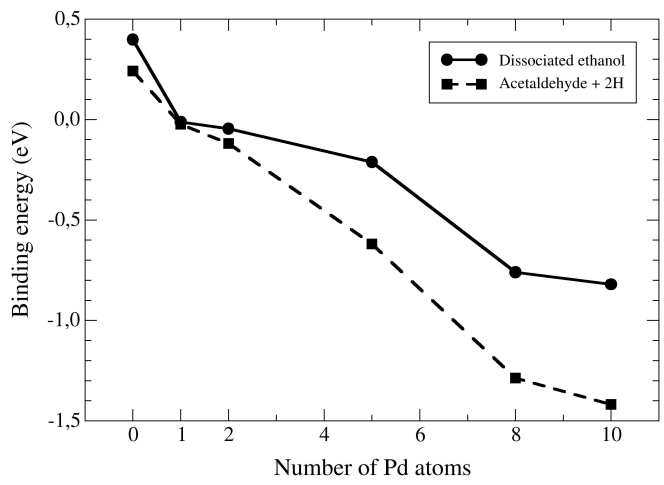

FIG. 8. Binding energy of dissociated ethanol and adsorbed acetaldehyde as a function of the number of Pd atoms $(x)$ in the mixed $\mathrm{Au}_{10-x} \mathrm{Pd}_{x}$ cluster.

Overall, binding energies of intermediate compounds and reaction barriers appear to vary in a complex way with the changing stoichiometry of these binary clusters. An interesting case is $\mathrm{Au}_{5} \mathrm{Pd}_{5}$, where the initial adsorption of ethanol has a larger binding energy than the corresponding configurations for Pd-rich alloys $\left(\mathrm{Au}_{2} \mathrm{Pd}_{8}\right.$ and $\left.\mathrm{Pd}_{10}\right)$. However, we have noticed that there is a correlation between the stability of several intermediate states (dissociated ethanol and adsorbed acetaldehyde) and the fraction of $\mathrm{Pd}$ atoms in the cluster. To reveal this feature, Figure 8 shows the binding energy of these two reaction intermediates against the concentration of palladium. A direct correlation is evident in both cases, with 
an increasing amount of palladium enhancing the relative stability of both dissociated ethanol and the adsorbed acetaldehyde.

Let us recall that the performance of a given catalyst critically depends on the stability of reaction intermediates. If those intermediates are too strongly bound (as in the case of pure palladium), reaction rates can actually decrease due to poisoning of the catalyst by the reaction products. On the other hand, if the binding of those intermediate species is too weak (typically, the case of pure gold) the probability for the initial reaction steps to take place drastically decreases, thus rendering the catalyst weakly active. According to this, the results in Figure 7 show that there exists a direct relationship between the Pd concentration and the overall performance of the binary catalysts, with an optimum behaviour being obtained for alloyed clusters.

\section{DISCUSSION AND CONCLUSIONS}

The comparison of the features for the reaction pathways at each composition reveals important changes as the relative concentration of gold and palladium varies. For pure $\mathrm{Au}_{10}$, the noble character of $\mathrm{Au}$ results in a high barrier for the initial $\mathrm{O}-\mathrm{H}$ dissociation. On the other hand, intermediate states (with either dissociated ethanol or adsorbed acetaldehyde) have small binding energies. This means that, although gold catalysts will be less reactive to ethanol dissociation, the latter part of the reaction will proceed much more effectively due to the easier removal of the reaction products (acetaldehyde and $\mathrm{H}_{2}$ ). Conversely, the pure $\mathrm{Pd}_{10}$ case is characterized by the opposite behaviour; namely, easier dissociation of the ethanol $\mathrm{O}-\mathrm{H}$ bond, and more difficult desorption of the products. This is due to the higher intrinsic reactivity of palladium, which produces (as suggested by the Brønsted-Evans-Polanyi mode ${ }^{39}$ ) lower energy barriers and higher binding energies.

One interesting feature caused by the higher reactivity of palladium is the formation of an acetaldehyde complex covalently bound to the $\mathrm{Pd}_{10}$ cluster, with transformation of the $\mathrm{O}=\mathrm{H}$ double bond into an $\mathrm{O}-\mathrm{H}$ single bond and formation of an oxymetallacycle with two covalent, $\mathrm{Pd}-\mathrm{O}$ and $\mathrm{Pd}-\mathrm{C}$ bonds. Such conformation is likely to be a precursor towards formation of complex reaction products by reaction between two adsorbed alcohol molecules. For example, by removing one $\mathrm{H}$ atom from the acetaldehyde complex, and adding a dissociated ethanol molecule (with formation of a new $\mathrm{C}-\mathrm{O}$ bond), ethyl acetate $\left(\mathrm{CH}_{3}-\right.$ COO- $\mathrm{CH}_{2}-\mathrm{CH}_{3}$ ) could be formed. In a similar way, experiments have found formation of benzyl benzoate at AuPd catalysts during the oxidation of benzyl alcohol, with concentrations varying with the catalyst composition.

Overall, the behaviour of Au-Pd alloy clusters can be interpreted in terms of the varying relative amounts of more reactive $\mathrm{Pd}$ and less reactive $\mathrm{Au}$ sites. In the case of $\mathrm{Au}_{2} \mathrm{Pd}_{8}$, all the main reaction steps take place at $\mathrm{Pd}$ sites, which have local environments analogous to the ones of the pure $\mathrm{Pd}_{10}$ cluster. This causes the reaction pathway to be very similar to the one for $\operatorname{Pd}_{10}$. The $\mathrm{Au}_{5} \mathrm{Pd}_{5}$ cluster is characterized by a uniform mixing of $\mathrm{Pd}$ and $\mathrm{Au}$ atoms, resulting in each site being surrounded by a mixture of $\mathrm{Pd}$ and $\mathrm{Au}$ sites. The reaction now involves the reactants and products binding to both types of atoms, slightly reducing the stability of the intermediate states (with respect to the $\mathrm{Pd}_{10}$ and $\mathrm{Au}_{2} \mathrm{Pd}_{8}$ cases), but keeping the reaction barriers lower than in the pure $\mathrm{Au}_{10}$ case. Finally, the $\mathrm{Au}_{8} \mathrm{Pd}_{2}$ case represents a situation where the two active $\mathrm{Pd}$ sites cause sizable deviations from the pure gold case; these sites attract ethanol, slightly reducing the height of the dissociation barrier. Also, they enhance binding of hydrogen, stabilizing some of the intermediate states.

Overall, the reactivity depends drastically on the amount of available $\mathrm{Pd}$ sites; a detailed analysis of the electronic structure of the alloyed clusters (shown in the Supplementary Information) gives additional insight into this. Partial densities of states (PDOS) show that the states nearer to the HOMO (which effectively correspond to the top of the $d$ valence band) are almost exclusively of $\mathrm{Pd}$-character, with the $\mathrm{Au}$ d-states having much lower energies. $\mathrm{Au}_{9} \mathrm{Pd}_{1}$ is an exception to the rule, with the states around the HOMO having both $\mathrm{Au}$ and $\mathrm{Pd}$ character. All these facts then agree with our observation of a marked preference (excepting $\mathrm{Au}_{9} \mathrm{Pd}_{1}$ ) towards initial binding of ethanol at $\mathrm{Pd}$ sites. Besides, by performing a Bader charge analysis (see Supplementary Information), we find that a slight charge transfer takes place from $\mathrm{Pd}$ to $\mathrm{Au}$ upon alloying. This leaves a small residual positive charge on the Pd sites, which helps to stabilize by favourable electrostatic interaction binding of the negatively charged oxygen atom in ethanol.

As a general conclusion, composition variations induce strong changes in the reaction features, which will affect both the activity and the selectivity of these model AuPd catalysts. In the case of alcohol oxidation, the most interesting cases are concentrations between $50 \%$ and $20 \% \mathrm{Pd}$, where the $\mathrm{Pd}$ atoms induce sizable reactivity changes due to higher binding energies of both reactants and products as compared to Au. In other words, clusters with those compositions combine the efficiency of palladium in lowering a bit the barrier to dissociate the first $\mathrm{H}$ atom and the efficiency of gold with respect to the later steps of the reaction. On the other hand, Pd-rich alloys show a behaviour almost analogous to the pure Pd case.

\section{ACKNOWLEDGMENTS}

Work supported by the Spanish MINECO (grant MAT2014-54378-R) and by Junta de Castilla y Leon (grant VA050U14). We acknowledge the support of the spanish supercomputing network (RES) by the computing time allocated at the Picasso node (University of 
Malaga).

${ }^{1}$ R. A. Sheldon, J. K. Kochi, Metal-catalyzed Oxidations of Organic Compounds, Academic Press, New York, 1981.

${ }^{2}$ T. Mallat, A. Baiker, Oxidation of alcohols with molecular oxygen on solid catalysts, Chem. Rev. 104 (2004) 3037-3058.

${ }^{3}$ A. S. K. Hashmi, G. J. Hutchings, Gold Catalysis, Angew. Chem. Int. Ed. 45 (2006) 7896-7936.

${ }^{4}$ A. Corma, H. Garcia, Supported gold nanoparticles as catalysts for organic reactions, Chem. Soc. Rev. 37 (2008) 2096-2126.

${ }^{5}$ Y. Zhang, X. Cui, F. Shi, Y. Deng, Nano-gold catalysis in fine chemical synthesis, Chem. Rev. 112 (2012) 2467-2505.

${ }^{6}$ A. Abad, P. Concepción, A. Corma, H. García, A collaborative effect between gold and a support induces the selective oxidation of alcohols, Angew. Chem. Int. Ed. 44 (2005) 4066-4069.

${ }^{7}$ Y. Guan, E. J. M. Hensen, Ethanol dehydrogenation by gold catalysts: The effect of the gold particle size and the presence of oxygen, Appl. Catal. A: Gen. 361 (2009) 49-56.

${ }^{8}$ M. Boronat, A. Corma, F. Illas, J. Radilla, T. Ródenas, M. J. Sabater, Mechanism of selective alcohol oxidation to aldehydes on gold catalysts: Influence of surface roughness on reactivity, J. Catal. 278 (2011) 50-58.

${ }^{9}$ K.-Q. Sun, S.-W. Luo, N. Xu, B.-Q. Xu, Gold nano-size effect in $\mathrm{Au} / \mathrm{SiO} 2$ for selective ethanol oxidation in aqueous solution, Catal. Lett. 124 (2008) 238-242.

${ }^{10}$ S. K. Klitgaard, A. T. DeLa Riva, S. Helveg, R. M. Werchmeister, C. H. Christensen, Aerobic oxidation of alcohols over gold catalysts: role of acid and base, Catal. Lett. 126 (2008) 213-217.

${ }^{11}$ R. Ferrando, J. Jellinek, R. L. Johnston, Nanoalloys: from theory to applications of alloy clusters and nanoparticles, Chem. Rev. 108 (2008) 845-910.

${ }^{12} \mathrm{~N}$. Toshima, T. Yonezawa, Bimetallic nanoparticles-novel materials for chemical and physical applications, New J. Chem. 22 (1998) 1179-1201.

${ }^{13}$ O. S. Alexeev, B. C. Gates, Supported bimetallic cluster catalysts, Ind. Eng. Chem. Res. 42 (2003) 1571-1587.

${ }^{14}$ M. Sankar, N. Dimitratos, P. J. Miedziak, P. P. Wells, C. J. Kiely, G. J. Hutchings, Designing bimetallic catalysts for a green and sustainable future, Chem. Soc. Rev. 41 (2012) 8099-8139.

${ }^{15}$ D. I. Enache, J. K. Edwards, P. Landon, B. Solsona-Espriu, A. F. Carley, A. A. Herzing, M. Watanabe, C. J. Kiely, D. W. Knight, G. J. Hutchings, Solvent-free oxidation of primary alcohols to aldehydes using Au-Pd/TiO2 catalysts, Science 311 (2006) 362365.

${ }^{16}$ T. A. G. Silva, E. Teixeira-Neto, N. López, L. M. Rossi, Volcanolike behavior of $\mathrm{Au}-\mathrm{Pd}$ core-shell nanoparticles in the selective oxidation of alcohols, Sci. Rep. 4 (2014) 5766.

${ }^{17}$ A. Villa, D. Wang, D. S. Su, L. Prati, New challenges in gold catalysis: bimetallic systems, Catal. Sci. Technol. 5 (2015) 5568.

${ }^{18}$ W.-B. Hou, N. A. Dehm, R. W. J. Scott, Alcohol oxidations in aqueous solutions using $\mathrm{Au}, \mathrm{Pd}$, and bimetallic AuPd nanoparticle catalysts, J. Catal. 253 (2008) 22-27.

${ }^{19} \mathrm{~S}$. Marx, A. Baiker, Beneficial interaction of gold and palladium in bimetallic catalysts for the selective oxidation of benzyl alcohol, J. Phys. Chem. C 113 (2009) 6191-6201.

${ }^{20}$ B. Zhu, I. C. Oğuz, H. Guesmi, Investigation of finite-size effects in chemical bonding of AuPd nanoalloys, J. Chem. Phys. 143 (2015) 144309.

${ }^{21}$ V. Soto-Verdugo, H. Metiu, Segregation at the surface of an $\mathrm{Au} / \mathrm{Pd}$ alloy exposed to CO, Surf. Sci. 601 (2007) 5332-5339.

${ }^{22}$ C.-R. Chang, B. Long, X.-F. Yang, J. Li, Theoretical studies on the synergetic effects of Au-Pd bimetallic catalysts in the selective oxidation of methanol, J. Phys. Chem. C 119 (2015) 16072-16081.

${ }^{23}$ J. J. Mortensen, L. B. Hansen, K. W. Jacobsen, Real-space grid implementation of the projector augmented wave method, Phys. Rev. B 71 (2005) 035109.

${ }^{24}$ J. Enkovaara, C. Rostgaard, J. J. Mortensen, J. Chen, M. Dulak, L. Ferrighi, J. Gavnholt, C. Glinsvad, V. Haikola, H. A. Hansen, H. H. Kristoffersen, M. Kuisma, A. H. Larsen, L. Lehtovaara, M. Ljungberg, O. Lopez-Acevedo, P. G. Moses, J. Ojanen, T. Olsen, V. Petzold, N. A. Romero, J. Stausholm-Møller, M. Strange, G. A. Tritsaris, M. Vanin, M. Walter, B. Hammer, H. Häkkinen, G. K. H. Madsen, R. M. Nieminen, J. K. Nørskov, M. Puska, T. T. Rantala, J. Schiøtz, K. S. Thygesen, K. W. Jacobsen, Electronic structure calculations with GPAW: a real-space implementation of the projector augmented-wave method, J. Phys. Condens. Matter 22 (2010) 253202.

${ }^{25}$ J. P. Perdew, K. Burke, M. Ernzerhof, Generalized gradient approximation made simple, Phys. Rev. Lett. 77 (1996) 3865-3868.

${ }^{26}$ M. A. L. Marques, M. J. T. Oliveira, T. Burnus, Libxc: a library of exchange and correlation functionals for density functional theory, Comput. Phys. Commun. 183 (2012) 2272-2281.

${ }^{27}$ D. C. Liu, J. Nocedal, On the limited memory BFGS method for large scale optimization, Math. Program. 45 (1989) 503-528.

${ }^{28}$ A. Alavi, P. Hu, T. Deutsch, P. L. Silvestrelli, J. Hutter, CO oxidation on $\mathrm{Pt}(111)$ : an ab initio density functional theory study, Phys. Rev. Lett. 80 (1998) 3650-3653.

${ }^{29}$ S. Grimme, J. Antony, S. Ehrlich, H. Krieg, A consistent and accurate ab initio parametrization of density functional dispersion correction (DFT-D) for the 94 elements H-Pu, J. Chem. Phys. 132 (2010) 154104.

${ }^{30}$ G. Zanti, D. Peeters, DFT study of bimetallic palladium-gold clusters PdnAum of low nuclearities $(\mathrm{n}+\mathrm{m} \leq 14)$, J. Phys. Chem. A 114 (2010) 10345-10356.

${ }^{31}$ I. Cabria, M. J. López, S. Fraile, J. A. Alonso, Adsorption and dissociation of molecular hydrogen on palladium clusters supported on graphene, J. Phys. Chem. C 116 (2012) 21179-21189.

${ }^{32}$ L. M. Molina, J. A. Alonso, Chemical properties of small Au clusters: an analysis of the local site reactivity, J. Phys. Chem. C 111 (2007) 6668-6677.

${ }^{33}$ F. Pittaway, L. O. Paz-Borbón, R. L. Johnston, H. Arslan, R. Ferrando, C. Mottet, G. Barcaro, A. Fortunelli, Theoretical studies of palladium-gold nanoclusters: Pd-Au clusters with up to 50 atoms, J. Phys. Chem. C 113 (2009) 9141-9152 .

${ }^{34}$ A. Bruma, R. Ismail, L. O. Paz-Borbón, H. Arslan, G. Barcaro, A. Fortunelli, Z. Y. Li, R. L. Johnston, DFT study of the structures and energetics of 98 -atom AuPd clusters, Nanoscale 5 (2013) 646-652.

${ }^{35}$ H. A. Hussein, J. B. A. Davis, R. L. Johnston, DFT global optimisation of gas-phase and $\mathrm{MgO}$-supported sub-nanometre AuPd clusters, Phys. Chem. Chem. Phys. 18 (2013) 26133-26143.

${ }^{36} \mathrm{H}$. Okamoto, T. B. Massalski, The Au-Pd (gold-palladium) system, Bull. Alloy Phase Diagr. 6 (1985) 229-235.

${ }^{37}$ P. Tereshchuk, J. L. F. Da Silva, Ethanol and water adsorption on close-packed $3 \mathrm{~d}, 4 \mathrm{~d}$, and $5 \mathrm{~d}$ transition-metal surfaces: a density functional theory investigation with van der Waals correction, J. Phys. Chem. C 116 (2012) 24695-24705.

${ }^{38}$ A. O. Pereira, C. R. Miranda, Atomic scale insights into ethanol oxidation on Pt, Pd and Au metallic nanofilms: a DFT with van der Waals interactions, Appl. Surf. Sci. 288 (2014) 564-571.

${ }^{39}$ P. Ferrin, D. Simonetti, S. Kandoi, E. Kunkes, J. A. Dumesic, J. K. Nørskov, M. Mavrikakis, Modeling ethanol decomposition on transition metals: a combined application of scaling and Brønsted-Evans-Polanyi relations, J. Am. Chem. Soc. 131 (2009) 5809-5815. 
Ab initio studies of ethanol dehydrogenation at binary AuPd nanocatalysts

Supplementary Information

\section{ADSORPTION OF MOLECULAR ETHANOL}

The following figures show the various equilibrium configurations and binding energies considered when searching for the most stable adsorption configuration of ethanol at $\mathrm{Au}_{x} \mathrm{Pd}_{y}$ clusters.

$$
\mathrm{CH}_{3}-\mathrm{CH}_{2}-\mathrm{OH} / \mathrm{Au}_{10}
$$

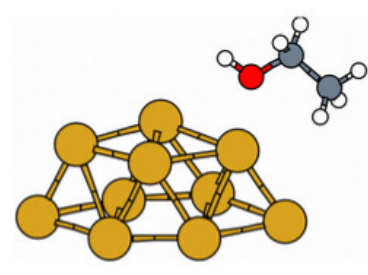

$E_{b}=-0.450 \mathrm{eV}$

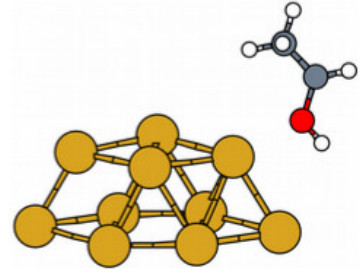

$E_{b}=-0.423 e V$

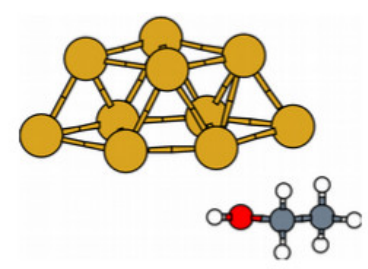

$E_{b}=-0.372 \mathrm{eV}$

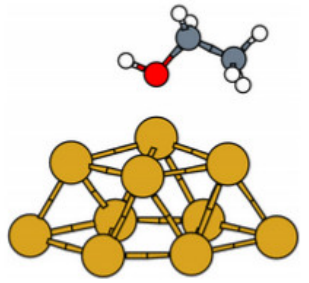

$E_{b}=-0.364 \mathrm{eV}$

$$
\mathrm{CH}_{3}-\mathrm{CH}_{2}-\mathrm{OH} / \mathrm{Au}_{9} \mathrm{Pd}_{1}
$$

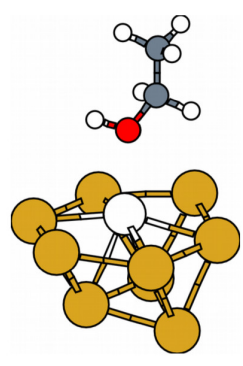

$E_{b}=-0.193 e V$

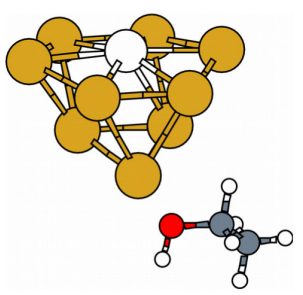

$E_{b}=-0.414 e V$

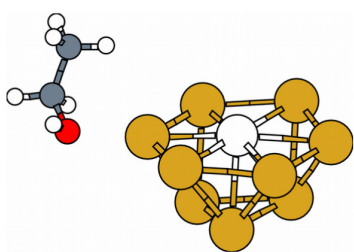

$E_{b}=-0.581 e V$

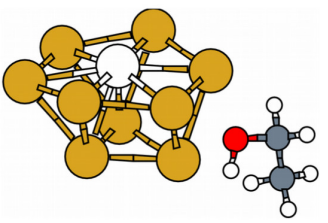

$E_{b}=-0.520 \mathrm{eV}$

\section{$\mathrm{CH}_{3}-\mathrm{CH}_{2}-\mathrm{OH} / \mathrm{Au}_{8} \mathrm{Pd}_{2}$}

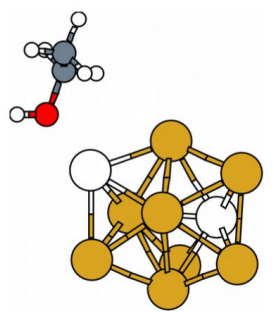

$E_{b}=-0.616 \mathrm{eV}$

$E_{b}=-0.398 \mathrm{eV}$
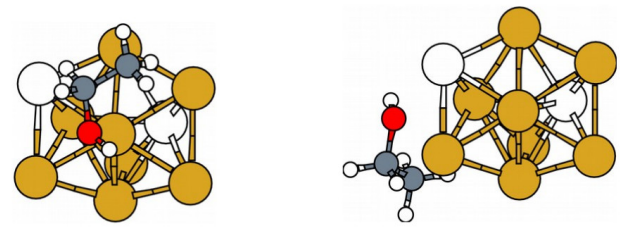

$E_{b}=-0.252 \mathrm{eV}$

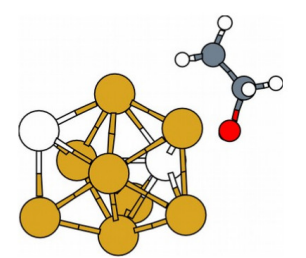

$E_{b}=-0.284 \mathrm{eV}$ 
$\mathrm{CH}_{3}-\mathrm{CH}_{2}-\mathrm{OH} / \mathrm{Au}_{5} \mathrm{Pd}_{5}$

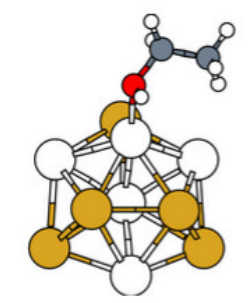

$E_{b}=-0.728 \mathrm{eV}$

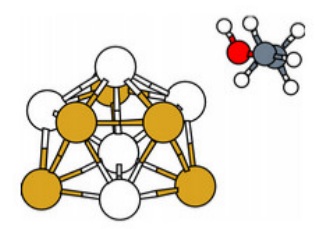

$E_{b}=-0.580 e V$

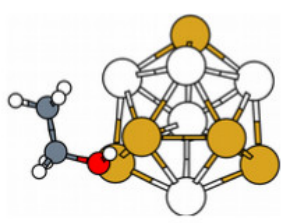

$E_{b}=-0.382 e V$

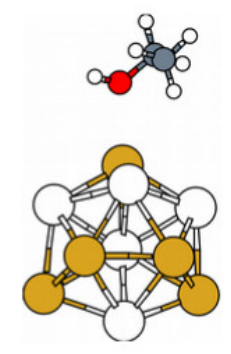

$E_{b}=-0.228 e V$
$\mathrm{CH}_{3}-\mathrm{CH}_{2}-\mathrm{OH} / \mathrm{Au}_{2} \mathrm{Pd}_{8}$

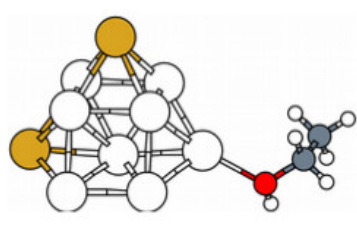

$E_{b}=-0.503 e V$

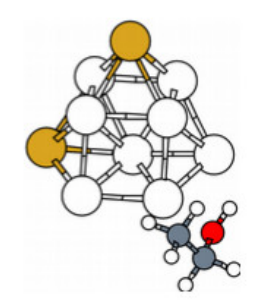

$E_{b}=-0.442 \mathrm{eV}$

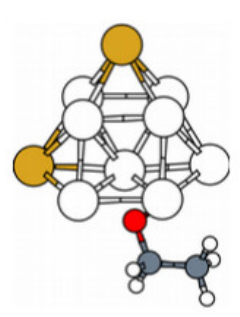

$E_{b}=-0.244 \mathrm{eV}$

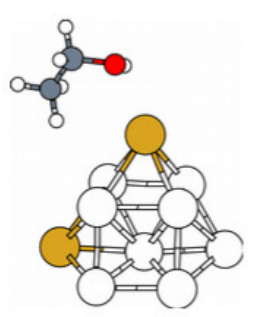

$E_{b}=-0.165 e V$
$\mathrm{CH}_{3}-\mathrm{CH}_{2}-\mathrm{OH} / \mathrm{Pd}_{10}$
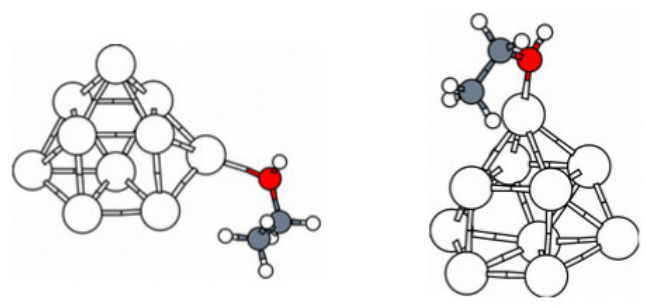

$E_{b}=-0.644 \mathrm{eV}$
$E_{b}=-0.548 \mathrm{eV}$
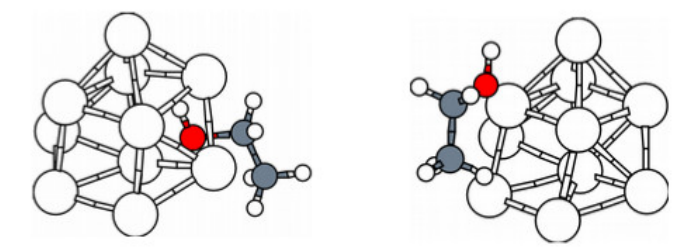

$E_{b}=-0.214 e V$ 


\section{SEARCH FOR TRANSITION STATES}

The following figure shows, as an example, the energies (as well as some confomations) of the intermediate configurations along the pathway for ethanol dissociation on $\mathrm{Au}_{2} \mathrm{Pd}_{8}$. The $\mathrm{O}-\mathrm{H}$ bond distance was taken as reaction coordinate and varied in intervals of $0.2 \AA$; each data in the plot corresponds to a constrained minimization of the structure. Around the candidate TS, the interval was decreased to $0.1 \AA$. Effectively, this procedure provides an accuracy on the search for the barrier height of the order of $0.02 \mathrm{eV}$.

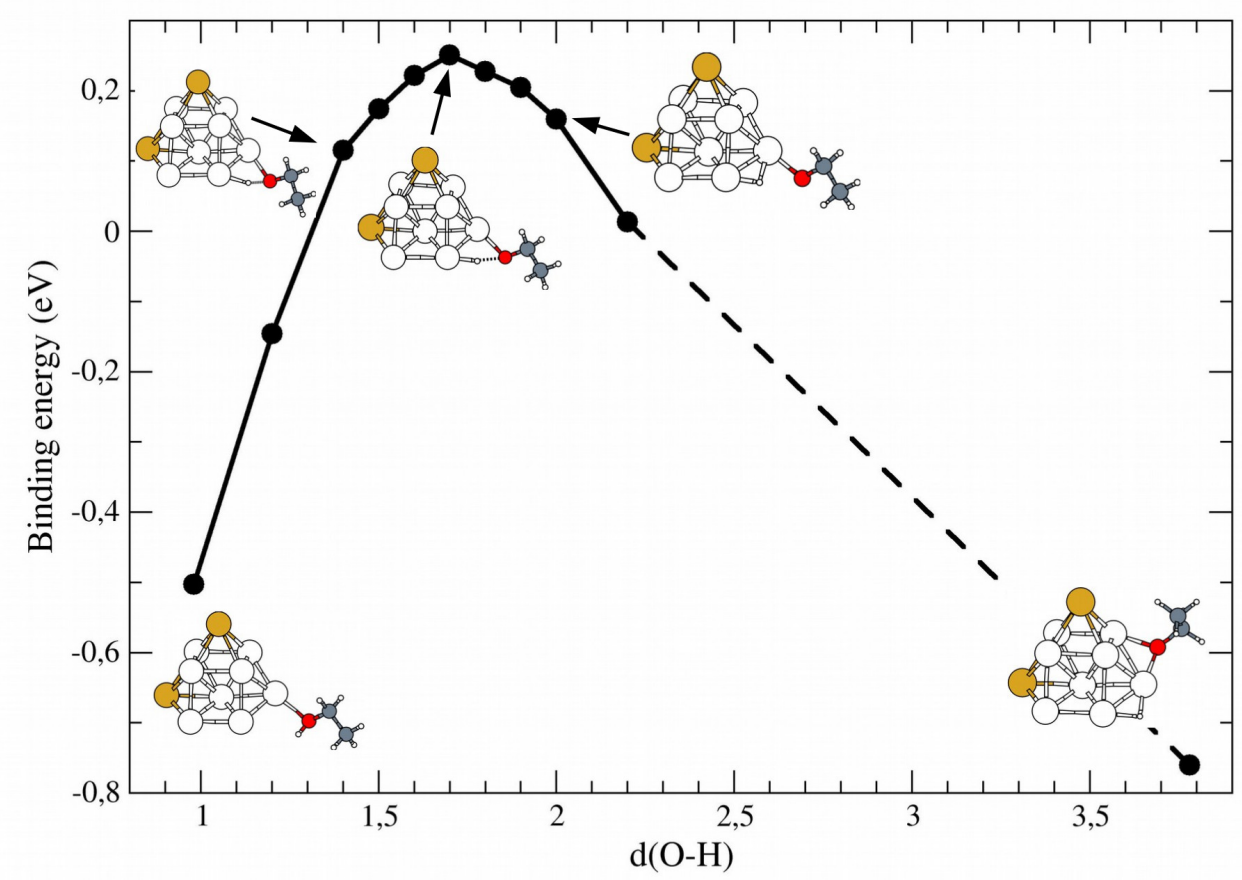




\section{ALTERNATE CONFORMATIONS OF AU $\mathbf{P D}_{8}$ AND AU $\mathrm{PD}_{2}$ : REACTION PATHWAYS}

In the case of the $20 \%$ and $80 \%$ conpositions, we have considered, besides of the conformations shown in the manuscript, other alternate ones with the two $\mathrm{Au}$ ( or $\mathrm{Pd}$ ) atoms neighbour to each other. Below we show the reaction pathways for ethanol dehydrogentation on each of these two conformations (which are slightly less stable -by around $0.1 \mathrm{eV}$ - than the ones reported in the manuscript). The results are quite similar to the ones for the most stable conformers. The larger differences are found in the $\mathrm{Au}_{8} \mathrm{Pd}_{2}$ case; having a $\mathrm{Pd}$ first neighbour produces some noticeable changes in the reactivity of the $\mathrm{Pd}$ atom where ethanol binds and dissociates.
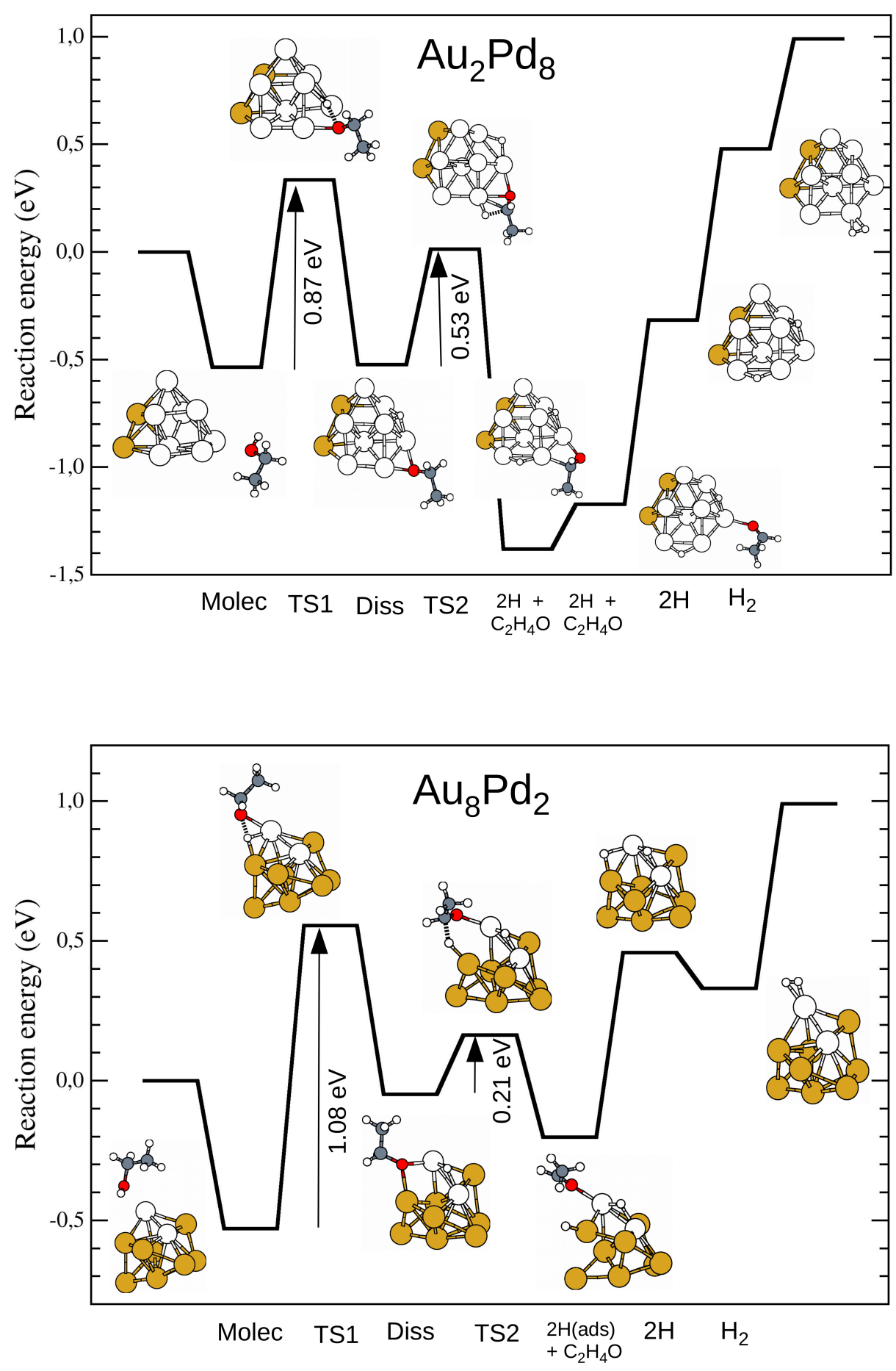


\section{BADER CHARGES ON ALLOYED CLUSTERS}

The figures show the value of the Bader charge on each atom for the alloyed clusters $\mathrm{Au}_{2} \mathrm{Pd}_{8}, \mathrm{Au}_{5} \mathrm{Pd}_{5}, \mathrm{Au}_{8} \mathrm{Pd}_{2}$ and $\mathrm{Au}_{9} \mathrm{Pd}_{1}$. There is a systematic tendency towads charge transfer from $\mathrm{Pd}$ to $\mathrm{Au}$.

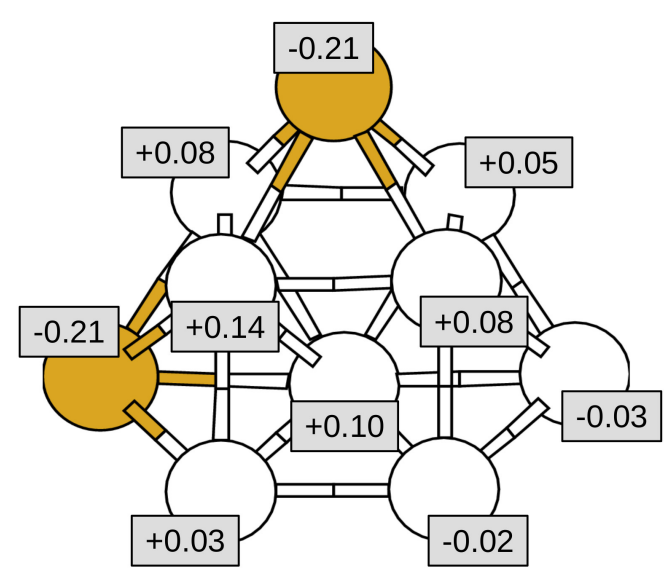

$\mathrm{Au}_{2} \mathrm{Pd}_{8}$

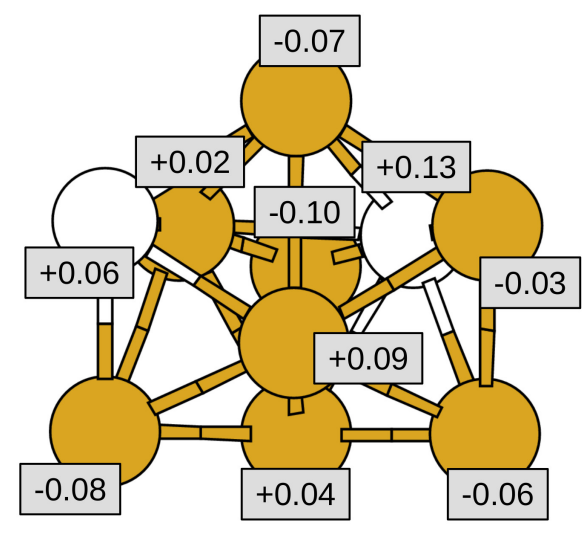

$\mathrm{Au}_{8} \mathrm{Pd}_{2}$

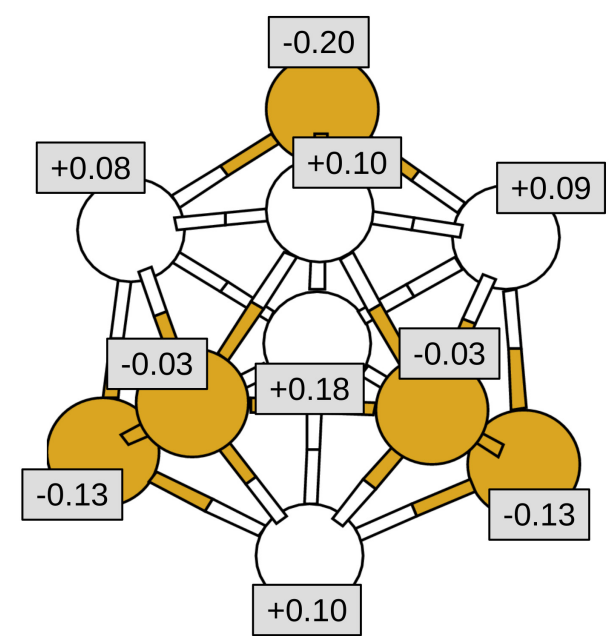

$\mathrm{Au}_{5} \mathrm{Pd}_{5}$

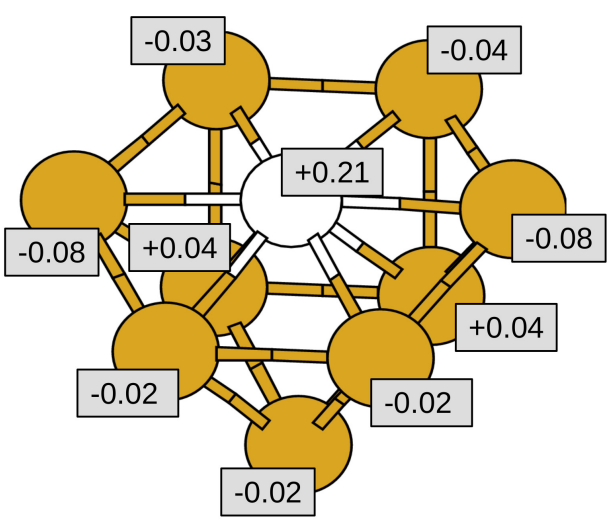

$\mathrm{Au}_{9} \mathrm{Pd}_{1}$ 


\section{ELECTRONIC STRUCTURE OF ALLOYED CLUSTERS}

The following pictures show, for each of the alloyed clusters, an analysis of the electronic density of states (DOS). We plot both the total and the partial DOS for the s and d orbitals of both gold and palladium. The palladium $\mathrm{d}$ states are always less stable than the gold d ones, which causes the top of the d band (where approximately the HOMO orbital is located) to have almost complete $\mathrm{Pd}$ character (with the exception of $\mathrm{Au}_{9} \mathrm{Pd}_{1}$ ).
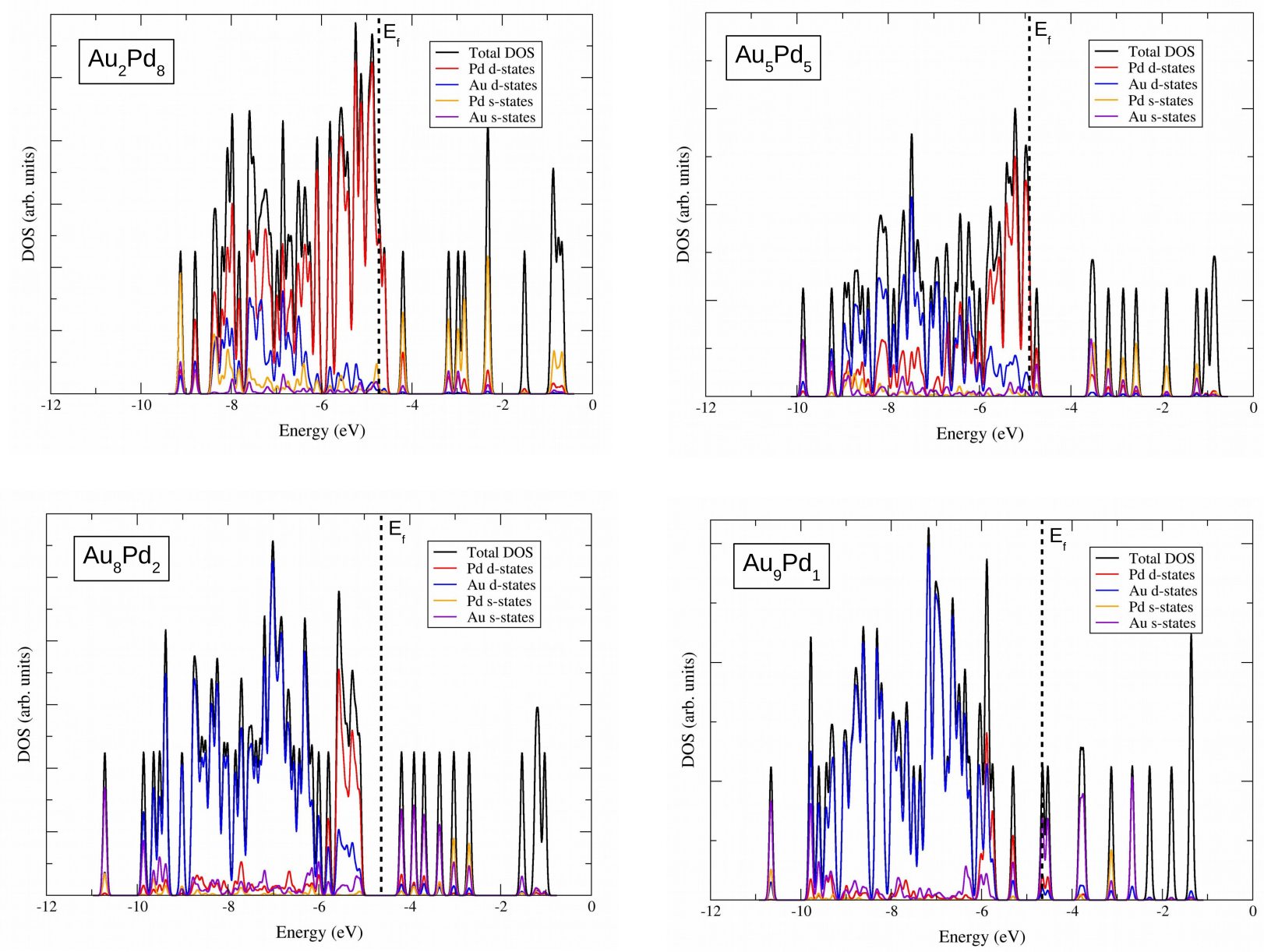